\title{
Pregnancy outcome in patients with fibroid: a retrospective study
}

\author{
Bintu H. Dadhania ${ }^{1 *}$, Shital T. Mehta1, Pushpa A. Yadava1, Bina M. Raval ${ }^{1}$, \\ Bhavi S. Shah ${ }^{1}$, Viditsinh P. Sisodiya ${ }^{1}$, Jay H. Dadhania ${ }^{2}$
}

\author{
${ }^{1}$ Department of Obstetrics and Gynecology, Smt. N. H. L. Municipal Medical College, SVPIMSR, Ahmedabad, \\ Gujarat, India \\ ${ }^{2}$ Department of Obstetrics and Gynecology, B. J. Medical College, Civil Hospital, Ahmedabad, Gujarat, India
}

Received: 23 July 2020

Revised: 14 September 2020

Accepted: 15 September 2020

\author{
*Correspondence: \\ Dr. Bintu H. Dadhania, \\ E-mail: dr.bintu.dadhania@gmail.com
}

Copyright: (c) the author(s), publisher and licensee Medip Academy. This is an open-access article distributed under the terms of the Creative Commons Attribution Non-Commercial License, which permits unrestricted non-commercial use, distribution, and reproduction in any medium, provided the original work is properly cited.

\begin{abstract}
Background: Fibroids are benign smooth muscle cell tumour of the uterus. In some patients of pregnancy associated with fibroid, it does not affect the outcome of pregnancy. On the other hand, various complications have been reported. The aim of our study was to evaluate the outcome in antenatal women with fibroids.

Methods: This retrospective study was conducted at tertiary care center, obstetrics \& gynecology department over a period of eighteen months between June 2018 to November 2019. Total 26 pregnant patients with $>3 \mathrm{~cm}$ fibroid was included in the study. They were followed during antenatal period. Maternal age, parity, size of fibroid, complications during pregnancy, labour, and delivery, mode of delivery and indications of cesarean section were noted.

Results: Out of 26 patients, $15(57.6 \%)$ were between 26-30 years of age group and $16(61.53 \%)$ were multigravidas. Normal vaginal delivery occurred in $8(33.33 \%)$, while $16(66.66 \%)$ delivered by caesarean section. There were 9 (34.61\%) patients who had no complication whereas $17(65.38 \%)$ had some complication. Pain was present in 8 $(30.76 \%)$. PROM and preterm labour were present in $3(18.75 \%)$ and $5(19.23 \%)$ respectively. PPH was present in 2 $(7.69 \%)$.

Conclusions: Pregnant patients who have fibroids are to be carefully screened in the antenatal period, so as to have a regular follow up. The widespread use of ultrasonography has facilitated diagnosis and management of fibroids in pregnancy. The site and size of fibroid is very important to predict its effect on pregnancy.
\end{abstract}

Keywords: Fibroid with pregnancy, Obstetric complication, Retrospective study

\section{INTRODUCTION}

Fibroids are benign smooth muscle cell tumour of the uterus. In some patients of pregnancy associated with fibroid, it does not affect the outcome of pregnancy. On the other hand, various complications have been reported. During antepartum period, it can lead to spontaneous abortion, pain, preterm labour, premature rupture of membrane (PROM) and malpresentations. During intrapartum period it leads to dysfunctional labour and increased rate of caesarean section whereas in postpartum period, it can cause retained placenta, post-partum haemorrhage (PPH), sepsis. It can cause fetal complica tions like intrauterine growth restriction (IUGR), low birth weight (LBW), intra-uterine death (IUD) etc. ${ }^{1}$

Main objective of this study was to evaluate the outcome and different complications of pregnancy associated with uterine fibroids in different age group in antepartum, intrapartum and post-partum period. 


\section{METHODS}

This retrospective study was carried out during June 2018 to November 2019 at department of obstetrics and gynecology, SVPIMSR hospital, Gujarat, India. All pregnant patients with fibroids $>3 \mathrm{~cm}$ was included in this study. Those patients having fibroid before pregnancy and later conceived, patients having fibroid diagnosed during pregnancy and patients having fibroid diagnosed at the time of delivery were included in study. All 26 patients were followed up clinically and ultrasonically. Data of all patients was recorded as per proforma and analyzed as per age, parity, mode of delivery and specific complications associated with pregnancy with fibroid.

\section{Inclusion criteria}

Inclusion criteria were the patients having fibroid before pregnancy and later conceived, patients having fibroid diagnosed during pregnancy and patients having fibroid diagnosed at the time of delivery were included in the study, fibroids $>3 \mathrm{~cm}$ in size, patients in antenatal \& intrapartum period admitted during period of June 2018 to November 2019.

\section{RESULTS}

During the study period, there were 8640 total deliveries. Out of these, there were 26 patients who had presented pregnancy associated with fibroid. Therefore, percentage of pregnancy with fibroid was $0.3 \%$ (Table 1) shows that incidence of pregnancy with fibroid in present study was $0.3 \%$.

Table 1: Incidence of pregnancy with fibroid.

\begin{tabular}{|ll|}
\hline Study & Incidence \\
\hline Present study & $0.3 \%$ \\
\hline Maliwad et al & $0.4 \%$ \\
\hline Poovathi et al & $0.075 \%$ \\
\hline Sarwar et al & $1 \%$ \\
\hline
\end{tabular}

As shown in (Table 2), majority of patients were in age group of 26-30 year which were $15(57.6 \%)$ while 9 $(34.6 \%)$ patients were in age group of $20-25$ years and 2 $(7.69 \%)$ patients were in $31-35$ years age group.

Table 2: Age of study population.

\begin{tabular}{|lll|}
\hline Age in years & $\mathbf{n = 2 6}$ & Percentage \\
\hline $\mathbf{2 0 - 2 5}$ & 9 & $34.6 \%$ \\
\hline $\mathbf{2 6 - 3 0}$ & 15 & $57.6 \%$ \\
\hline $\mathbf{3 1 - 3 5}$ & 2 & $7.69 \%$ \\
\hline
\end{tabular}

As shown in (Table 3), fibroids were more frequent in multigravida $16(61.53 \%)$ and primigravida were 10 $(38.46 \%)$.
Table 3: Parity wise distribution.

\begin{tabular}{|lll|}
\hline Gravidity & $\mathbf{n = 2 6}$ & Percentage \\
\hline Primigravida & 10 & $38.46 \%$ \\
\hline Multigravida & 16 & $61.53 \%$ \\
\hline
\end{tabular}

Here, (Table 4) shows complications of pregnancy associated with fibroid. $9(34.61 \%)$ patients remained asymptomatic. The most common complication in pregnancy as per this study was pain in abdomen in 8 $(30.76 \%)$ patients followed by preterm labour in 5 $(19.23 \%)$. Spontaneous miscarriage and PPH occurred in $2(7.69 \%)$ patients.

Table 4: Complications during pregnancy.

\begin{tabular}{|lll|}
\hline Complication & n=26 & Percentage \\
\hline Asymptomatic & 9 & $34.61 \%$ \\
\hline Spontaneous Miscarriage & 2 & $7.69 \%$ \\
\hline Pain in abdomen & 8 & $30.76 \%$ \\
\hline PPH & 2 & $7.69 \%$ \\
\hline Preterm labour & 5 & $19.23 \%$ \\
\hline
\end{tabular}

As shown in (Table 5), caesarean section was most common mode of termination of pregnancy in 16 $(66.66 \%)$ of which preterm labour was higher $(75 \%) .8$ patients $(33.33 \%)$ were delivered by spontaneous vaginal delivery of which $50 \%$ were preterm.

Table 5: Mode of delivery.

\begin{tabular}{|c|c|c|c|c|}
\hline \multicolumn{3}{|c|}{ Mode of delivery } & $n=26$ & Percentage \\
\hline \multirow{2}{*}{ SVD } & Term & 4 & \multirow{2}{*}{8} & \multirow{2}{*}{$33.33 \%$} \\
\hline & Preterm & 4 & & \\
\hline \multirow{2}{*}{ LSCS } & Term & 4 & \multirow{2}{*}{16} & \multirow{2}{*}{$66.66 \%$} \\
\hline & Preterm & 12 & & \\
\hline
\end{tabular}

SVD- spontaneous vaginal delivery, LSCS- lower (uterine) segment caesarean section

As shown in (Table 6), indications for LSCS were malpresentation in $2(12.5 \%)$ women, 4 (25\%) women were with post-caesarean pregnancy, placenta previa in 3 (18.75\%), PROM with poor bishop's score in 3 (18.75\%), uterine inertia in $2(12.5 \%) \&$ non progressive labor in 2 $(12.5 \%)$.

Table 6: Indication for LSCS.

\begin{tabular}{|lll|}
\hline Elective Caesarian Section & $\mathbf{n = 1 6}$ & Percentage \\
\hline Malpresentation & 2 & $12.5 \%$ \\
\hline Placenta previa & 3 & $18.75 \%$ \\
\hline Post-caesarian pregnancy & 4 & $25 \%$ \\
\hline $\begin{array}{l}\text { PROM with poor bishop } \\
\text { score }\end{array}$ & 3 & $18.75 \%$ \\
\hline Uterine inertia & 2 & $12.5 \%$ \\
\hline Non-progressive labour & 2 & $12.5 \%$ \\
\hline
\end{tabular}




\section{DISCUSSION}

In present study, percentage of pregnancy with fibroid was $0.3 \%$ which is comparable to study by Maliwad et al various studies have reported incidence of pregnancy with fibroid as $0.09 \%$ to $3.7 \%$. $^{2,4}$

Mean maternal age in this study was found to be 26.65 years. The age of study population in this study is comparable to the study by Maliwad et al According to various studies, it is seen that occurrence of leiomyomas in second and third decades of life is significant because it can affect the conception \& complicate in pregnancy. ${ }^{2,5}$

In this study, we found that fibroids were less frequent in the primigravidae compared to multigravida. This is consistent with earlier studies by Sarwar et al $(63 \%$ multigravida and $37 \%$ primigravida). ${ }^{6}$

In this study, large majority of patients 9 (34.61\%) remained asymptomatic in pregnancy $\&$ abortion rate was $2(7.69 \%)$. Various studies have reported abortion rate between 14-22\%.-9 Both patients, who aborted, had submucous fibroid and placental attachment was on the fibroid as per USG. Location of the fibroid is important. Spontaneous miscarriage is more common with fibroids located in the uterine corpus (body) than in the lower uterine segment and in women with intramural or submucosal fibroids. ${ }^{11}$ If embryo chooses to implant at that site, the fibroid may interfere with normal placentation \& development of definitive uteroplacental circulation due to distorted vascular architecture \& leads to spontaneous pregnancy loss. Multiple fibroids may increase the miscarriage rate compared with presence of single fibroid only (23.6\% vs $8.0 \%){ }^{9}$

Pain is most commonly reported complaint and is seen most often in women with larger fibroids during 2 nd and 3rd trimester of pregnancy. ${ }^{8}$ In this study, patients who suffered from pain due to fibroid in their antepartum period were $8(30.76 \%)$. Pain can occur if a fibroid undergoes red degeneration. ${ }^{10} \mathrm{~A}$ heterogeneous echogenic pattern or cystic changes on ultrasound indicates the development of red degeneration. Three theories have been proposed to explain the severe pain. First, that rapid fibroid growth results in the tissue outgrowing its blood supply leading to tissue anoxia, necrosis and infarction. Second, that the growing uterus results in a change in the architecture (kinking) of the blood supply to the fibroid leading to ischemia and necrosis even in the absence of fibroid growth. Third, that the pain results from the release of prostaglandins from cellular damage within the fibroid. ${ }^{15}$

In present study, preterm labour occurred in 5 (19.23\%) patients. PROM occurred in $3(18.75 \%)$ patients. The reason that fibroid uteri are less distensible than nonfibroid uteri, while decreased oxytocinase activity in gravid fibroid uterus, which may result in localized increase in oxytocin levels leading to premature contractions and premature labour. ${ }^{12,13}$

PPH occurred in $2(7.69 \%)$ patients. Fibroids may distort the uterine architecture and interfere with myometrial contractions leading to uterine atony and postpartum haemorrhage. ${ }^{14}$

Women with fibroids were at a 3.7-fold increased risk of cesarean delievery. ${ }^{8}$ Caesarean incidence in this study $(66.66 \%)$ is similar to studies by Maliwad et al $(80 \%){ }^{2}$ Malpresentation, large fibroids, and fibroids in lower uterine segment are considered predisposing factors for cesarean delivery. ${ }^{11}$ Indications for caesarean section in this study were comparable to study by Poovathi et al. ${ }^{3}$

\section{CONCLUSION}

Pregnancies with fibroids are associated with complications during antepartum, intrapartum, and postpartum period. They need frequent follow-up and evaluation. The site and size of fibroid is very important to predict its effect on the pregnancy. These pregnancies are associated with increased incidence of caesarean delivery and PPH and considered as high risk.

\section{Funding: No funding sources Conflict of interest: None declared Ethical approval: Not required}

\section{REFERENCES}

1. Ouyang DW, Economy KE, Norwitz ER. Obstetric complications of fibroids, Obstetrics and Gynecology Clinics of North America, 2006;33:153-69.

2. Maliwad AK, Thaker R, Shah P. Pregnancy outcome in patients with fibroid. Int J Reproduct Contracep Obstet Gynecol. 2014;3(3):743.

3. Poovathi M, Ramalingam R. Maternal and Fetal Outcome in Pregnancy with Fibroids: A Prospective Study. Int J Scientif Stud, 2016;3(11):169-72.

4. Suchitra P, Sanjay R, Ranjit A. Pregnancy with fibroid. in: Suchitra P, Sanjay R, Ranjit A, (eds.), Fibroids 1st ed., Mumbai: The National Book Depot, 2006:136-46.

5. Cramer SF, Patel A. The frequency of uterine leiomyomas, Americ J Clinic Pathol. 1990;94:435-8.

6. Sarwar I, Habib S, Bibi A, Malik N, Parveen Z. Clinical audit of foetomaternal outcome in pregnancies with fibroid uterus. J Ayu Medic Colleg Abbottab. 2012;24:79-82.

7. Shailesh Kaur, Anantta Pandole, Aparna Hegde, Sangeeta Kulkarni, Miti Ahuja, V. R. Ambiye. Pregnancy with fibroids, J Obstet Gynecol Ind. 2004; 54(4):361-2.

8. Klastsky PC, Tran ND, Caughey AB, Fujimoto VY. Fibroids and reproductive outcomes: a systematic literature review from conception to delivery, Americ J Obstet Gynecol. 2008;19:357-66. 
9. Benson CB, Chow JS, Chang-Lee W, Hill JA 3rd, Doubilet PM. Outcome of pregnancies in women with uterine leiomyomas identified by sonography in the first trimester. J Clinic Ultrasou. 2001;29:261-4.

10. Gupta S, Manyonda IT. Acute complications of fibroids. Bes Pract Resear Clinic Obstet Gynaecol. 2009;23(5):609-17.

11. Lev-Toaff AS, Coleman BG, Arger PH, Mintz MC, Arenson RL, Toaff ME. Leiomyomas in pregnancy: sonographic study. Radiol. 1987;164(2):375-80.

12. Rice JP, Kay HH, Mahony BS. The clinical significance of uterine leiomyomas in pregnancy, Americ J Obstet Gynecol. 1989;160:1212-6.

13. Blum M. Comparative study of serum CAP activity during pregnancy in malformed and normal uterus, $\mathrm{J}$ Perina Medic. 1978;6:165-8.
14. Szamatowicz J, Laudanski T, Bulkszaz B, Akerlund M. Fibromyomas and uterine contractions, Acta Obstetricia et Gynecologica Scandinavica. 1997; 76:973-6.

15. Lee HJ, Norwitz ER, Shaw J. Contemporary management of fibroids in pregnancy. Rev Obstet Gynecol. 2010;3(1):20-7.

Cite this article as: Dadhania $\mathrm{BH}$, Mehta ST, Yadava PA, Raval BM, Shah BS, Sisodiya VP. Preg nancy outcome in patients with fibroid: a retrospect tive study. Int J Reprod Contracept Obstet Gynecol 2020;9:4428-31. 